\title{
Predictors of Outcome in Patients With Fibrolamellar Carcinoma: Analysis of the National Cancer Database
}

\author{
HUSSEIN A. ASSI ${ }^{1}$, SARBAJIT MUKHERJEE ${ }^{2}$, MICHAEL MACHIORLATTI ${ }^{3}$, \\ SARA VESELY $^{3}$, VIPUL PAREEK ${ }^{1}$ and HASSAN HATOUM ${ }^{1}$ \\ ${ }^{1}$ Department of Medicine, Division of Hematology-Oncology, Stephenson Cancer Center, \\ University of Oklahoma Health Sciences Center, Oklahoma City, OK, U.S.A.; \\ ${ }^{2}$ Department of Medicine, Roswell Park Comprehensive Cancer, University of Buffalo, Buffalo, NY, U.S.A.; \\ ${ }^{3}$ Department of Biostatistics and Epidemiology, College of Public Health, \\ University of Oklahoma Health Sciences Center, Oklahoma City, OK, U.S.A.
}

\begin{abstract}
Background: Fibrolamellar carcinoma (FLC) is a very rare liver tumor. We aimed to retrospectively analyze the clinicopathological factors and treatment modalities affecting overall survival (OS) in FLC. The objective of the study was to identify predictors of survival in FLC. Patients and Methods: Using the National Cancer Database, we identified 496 patients diagnosed with FLC between 2004 and 2015. Clinicopathological, treatment, and survival data were collected. Results: Hepatic resection was performed on $254(51.2 \%)$ patients, liver-directed therapy on 13 (2.6\%) patients, and liver transplantation on 15 (3.0\%) patients. Median OS by stage were 142.1, 87.2, 32.3, and 14.1 months for stages 1, 2, 3, and 4, respectively. Metastatectomy was not associated with superior median OS (23.4 vs. 10.5 months, $p=0.163$ ). Age $\leq 40$, low Charlson-Deyo comorbidity score, early stage and hepatic resection were independently associated with longer OS. Conclusion: Our study reports current trends in FLC management, and identifies independent predictors of $\mathrm{OS}$.
\end{abstract}

Hepatocellular carcinoma (HCC) is the second most common cause of cancer-related deaths worldwide (1). In the United States, the incidence of HCC is rising faster than that of any other cancer, both in men and women (2). Historically,

This article is freely accessible online.

Correspondence to: Hussein Assi, MD, Department of Medicine, Division of Hematology-Oncology, Stephenson Cancer Center, University of Oklahoma Health Sciences Center, 800 NE 10th St., 6th Floor, Oklahoma City, OK 73104, U.S.A. Tel: +1 4052714022, Fax: +1 4052714221, e-mail: hussein-assi@ouhsc.edu

Key Words: Fibrolamellar, hepatocellular carcinoma, prognosis, outcome. fibrolamellar carcinoma (FLC) was classified as a rare variant of HCC, comprising only $0.4-5 \%$ of all primary liver tumors in the United Sates (3, 4). However, FLC has a unique pathogenesis, with distinct histological, clinical, and epidemiological characteristics compared to conventional HCC $(4,5)$. FLC occurs in a distinct population, usually in young patients without the presence of liver cirrhosis or viral hepatitis $(6,7)$. A characteristic somatic gene fusion, namely DNAJB1-PRKACA, has been discovered as the primary oncogenic driver in FLC, with subsequent studies confirming its presence in $79-100 \%$ of FLC cases (8-10). In addition, FLC appears to have a more stable genome in comparison to HCC, with fewer somatic mutations and lower levels of promoter methylation (7, 11-13). This difference in tumor biology and clinicopathological features necessitates a better understanding of factors influencing outcomes in patients with FLC.

Due to the rarity of this tumor, management of FLC has posed several challenges to physicians, and treatment approaches have been largely extrapolated from that of HCC $(6,14-17)$. Liver resection remain the only potentially curative treatment options $(6,18,19)$. For unresectable disease, there is no standard of care, and several treatment modalities have been implemented, including chemotherapy, liver-directed therapy (LDT), and external beam radiotherapy $(14,20-22)$. However, these current practices are generally based on small institutional retrospective studies and case series, and therefore lack the statistical power to draw robust conclusions (17). As such, querying large national databases may better delineate patterns of care and outcome in lowincidence cancers such as FLC.

The present study sought to perform a comprehensive analysis of the clinicopathological characteristics, treatment modalities, and outcome of patients with FLC from the National Cancer Database (NCDB). We also aimed to compare our findings to historical data on conventional 
HCC, as well as identifying independent prognostic factors in FLC patients.

\section{Patients and Methods}

Data source. The NCDB is a joint project of the Commission on Cancer $(\mathrm{CoC})$ of the American College of Surgeons and the American Cancer Society. The NCDB captures information from approximately $1,500 \mathrm{CoC}$-accredited hospitals and $>70 \%$ of all newly-diagnosed malignancies in the USA. All data within the NCDB are de-identified of specific patient and hospital factors and are thus in compliance with the Health Insurance Portability and Accountability Act (HIPAA).

Study design. An NCDB participant Use Data File containing data on patients with liver cancer was obtained. Patients diagnosed with FLC were identified using the diagnostic histology code 8171 associated with FLC as per the International Classification of Diseases for Oncology $3^{\text {rd }}$ edition (ICD-O-3 code) (23). Patients' clinicopathological characteristics and treatment modalities were analyzed using frequency statistics and the Chi-square method. Covariates included age, sex, race, Charlson-Deyo Score, grade, tumor size, pathological regional lymph nodes $(\mathrm{pN}+)$, stage, alphafetoprotein (AFP) level, local therapy, chemotherapy, and radiation therapy. Local therapy was further categorized into hepatic resection (which includes any type of liver resection), LDT, and liver transplantation. The disease stage was determined according to the American Joint Committee on Cancer (AJCC) staging system of primary liver cancer, $7^{\text {th }}$ edition. The Charlson-Deyo score is a weighted score derived from the sum of the scores for each of the comorbid conditions listed in the Charlson Comorbidity Score Mapping Table (24). Overall survival (OS) was defined as the number of months between date of diagnosis and date of death (if known) or last follow-up (last known alive date). Follow-up time was calculated from the date of diagnosis to the last date of contact. AFP level $>20 \mathrm{ng} / \mathrm{ml}$ was considered positive as per the American Association for the Study of Liver Diseases (25). This study was determined by the institutional review board to be exempt as a result of the de-identified nature of the data.

Statistical analysis. Patient clinicopathological categorical characteristics were reported using frequency statistics (n and \%). For continuous variables, the median and interquartile range (IQR) were reported. Wilcoxon rank sum test was performed to compare medians. Kaplan-Meier Survival analysis and plots were created for all covariates to determine unadjusted OS. The log-rank test was used to determine significant associations between covariates and OS. Variables that showed significance with OS on a univariate basis or were potential confounders were included in Cox proportional hazards model for multivariable analysis. Hazard ratios with $p$-values $<0.05$ were considered statistically significant. SAS 9.4 was used to perform all analysis.

\section{Results}

Patient and tumor characteristics. Using the NCDB, we identified a total of 496 patients diagnosed with FLC between 2004 and 2015. The demographic and clinical characteristics of these patients are presented in Table I. The
Table I. Descriptive statistics for patients with FLC in the NCDB registry between 2004 and 2015.

\begin{tabular}{|c|c|}
\hline Characteristics & $\begin{array}{l}\text { All patients } \\
(\mathrm{n}=496)\end{array}$ \\
\hline \multicolumn{2}{|l|}{ Age (years), n (\%) } \\
\hline$<40$ & $301(60.7)$ \\
\hline$\geq 40$ & $195(39.3)$ \\
\hline Median (IQR) & $32(23-59)$ \\
\hline \multicolumn{2}{|l|}{ Gender, n (\%) } \\
\hline Male & 277 (55.9) \\
\hline Female & $219(44.1)$ \\
\hline \multicolumn{2}{|l|}{ Race, n (\%) } \\
\hline White & $346(69.7)$ \\
\hline Black & $54(10.9)$ \\
\hline Hispanic & $58(11.7)$ \\
\hline Other & $38(7.7)$ \\
\hline \multicolumn{2}{|l|}{ Charlson-Deyo Score, n (\%) } \\
\hline 0 & $383(77.2)$ \\
\hline 1 & $67(13.5)$ \\
\hline 2 & $18(3.6)$ \\
\hline 3 & $28(5.7)$ \\
\hline \multicolumn{2}{|l|}{ Tumor size $(\mathrm{cm})$} \\
\hline Median (IQR) & $9.5(5.9-13.0)$ \\
\hline \multicolumn{2}{|c|}{ Pathologic regional LNs $(\mathrm{pN}+), \mathrm{n}(\%)$} \\
\hline No & $80(16.5)$ \\
\hline Yes & $70(14.5)$ \\
\hline Unknown & $334(69)$ \\
\hline \multicolumn{2}{|l|}{ Stage, n (\%) } \\
\hline 1 & $114(31.2)$ \\
\hline 2 & $43(11.8)$ \\
\hline 3 & $89(24.3)$ \\
\hline 4 & $120(32.8)$ \\
\hline \multicolumn{2}{|l|}{ Grade, n (\%) } \\
\hline Well-differentiated & $46(9.3)$ \\
\hline Moderately differentiated & $127(25.6)$ \\
\hline Poorly differentiated & $37(7.5)$ \\
\hline Undifferentiated & $3(0.6)$ \\
\hline Unknown & $283(57.1)$ \\
\hline \multicolumn{2}{|l|}{ AFP, n (\%) } \\
\hline Negative & $196(39.5)$ \\
\hline Positive & $146(29.4)$ \\
\hline Unknown & $154(31.1)$ \\
\hline
\end{tabular}

IQR: Interquartile range; LN: lymph node; AFP: alpha-fetoprotein.

median age at diagnosis was 32 years. Fifty-six percent of patients were males. Most patients (77.2\%) had a CharlsonDeyo Score of 0, reflecting the fact that FLC tends to occur in otherwise healthy patients. With respect to tumor characteristics, the median tumor size was $9.5 \mathrm{~cm}$. Out of 120 patients with stage IV disease at diagnosis, 15 (12.5\%) and $52(43.3 \%)$ patients had stage IVA and IVB disease, respectively, with the remaining $53(44.2 \%)$ patients being unspecified. In patients with distant metastasis, lung, bone, and brain metastasis were reported in $26(50 \%), 10(19.2 \%)$ patients, and $1(1.9 \%)$ of patient, respectively. Data on grade and $\mathrm{pN}+$ status was missing in a significant proportion of 
Table II. Treatment modalities of FLC patients.

\begin{tabular}{lc}
\hline Treatment & $\begin{array}{c}\text { All patients } \\
\mathrm{n}=496\end{array}$ \\
\hline Local therapy, n (\%) & \\
Hepatic resection & $254(51.2)$ \\
Liver-directed therapy & $13(2.6)$ \\
Liver transplantation & $15(3.0)$ \\
No local therapy & $214(43.2)$ \\
Regional LN surgery, n (\%) & $146(30.2)$ \\
Chemotherapy, n (\%) & \\
No & $300(60.5)$ \\
Yes & $180(36.3)$ \\
Unknown & $16(3.2)$ \\
Radiation therapy, n (\%) & \\
No & $450(90.7)$ \\
Yes & $42(8.5)$ \\
Unknown & $4(0.8)$ \\
\hline
\end{tabular}

LN: Lymph node.

patients. AFP was positive in 146 patients (29.4\%); however, only 27 patients $(5.4 \%)$ had an AFP level $>400 \mathrm{ng} / \mathrm{ml}$. As far as management is concerned, local therapy was performed on $56.8 \%$ of patients. The majority consisted of hepatic resection, representing over $90 \%$ of local interventions. Details on the use of different treatment modalities are presented in Table II. Among FLC patients with metastatic disease, $19(15.8 \%)$ of patients underwent metastatectomy.

Univariate analysis of outcome. Survival data were available on 461 FLC patients. Using Kaplan-Meier survival analyses, unadjusted median OS stratified by various covariates were calculated (Table III). Age $\geq 40$, male gender, non-white race, high Charlson-Deyo Score, tumor size $\geq 10 \mathrm{~cm}, \mathrm{pN}+$ status, higher stage, higher grade, and AFP positivity were all associated with poor OS. Concerning the association between different treatment modalities and outcome, hepatic resection, chemotherapy, and radiation therapy were evaluated individually. LDT and liver transplantation were excluded from the survival analysis due to the small sample size, precluding from drawing meaningful conclusions. Patients undergoing hepatic resection had a significantly higher median OS compared to those who did not (68.5 vs. 10.3 months, $p=0.001$ ). Patients who received chemotherapy in any setting (i.e. neoadjuvant, adjuvant, or metastatic) had a worse median OS compared those who did not receive chemotherapy (42.8 vs. 22 months, $p=0.001)$. Interestingly, when the analysis was limited to FLC patients who underwent local therapy, adjuvant/neoadjuvant chemotherapy was still associated with worse median OS [44.0 (95\%CI=38.5-51.8) vs. 97.1 (95\%CI=76.7-142.1) months, respectively; $p=0.001$ ] (Figure 1). Only 12 patients received neoadjuvant chemotherapy; thus, a sub-analysis of this group
Table III. Kaplan-Meier product limit survival analysis (OS)-Median OS with $95 \%$ CI.

\begin{tabular}{|c|c|c|c|}
\hline Variable & $\begin{array}{c}\text { Total } \\
\text { number of } \\
\text { patients (n) }\end{array}$ & $\begin{array}{c}\text { Median OS } \\
\text { in months } \\
(95 \% \mathrm{CI})\end{array}$ & $p$-Value \\
\hline \multicolumn{4}{|l|}{ Age (years) } \\
\hline$<40$ & \multirow[t]{2}{*}{461} & $39.9(33.5-47.9)$ & \multirow[t]{2}{*}{$<0.001$} \\
\hline$\geq 40$ & & $15.7(9.9-26.6)$ & \\
\hline \multicolumn{4}{|l|}{ Gender } \\
\hline Male & \multirow{2}{*}{461} & $24.3(20.1-34.5)$ & \multirow{2}{*}{0.004} \\
\hline Female & & $40.6(32.5-54.6)$ & \\
\hline \multicolumn{4}{|l|}{ Race } \\
\hline White & \multirow[t]{4}{*}{461} & $39.5(32.5-47.9)$ & \multirow[t]{4}{*}{0.048} \\
\hline Black & & $19.7(11.0-33.7)$ & \\
\hline Hispanic & & $19.7(8.3-33.5)$ & \\
\hline Other & & $13.3(7.3-87.2)$ & \\
\hline \multicolumn{4}{|l|}{ Charlson-Deyo score } \\
\hline 0 & \multirow[t]{4}{*}{461} & $39.4(28.6-47.9)$ & \multirow[t]{4}{*}{$<0.001$} \\
\hline 1 & & $39.0(20.5-56.2)$ & \\
\hline 2 & & $9.2(3.5-40.1)$ & \\
\hline 3 & & $4.0(0.8-6.4)$ & \\
\hline \multicolumn{4}{|l|}{ Tumor size } \\
\hline$<10 \mathrm{~cm}$ & \multirow[t]{2}{*}{411} & $47.9(37.8-70.9)$ & \multirow[t]{2}{*}{0.025} \\
\hline$\geq 10 \mathrm{~cm}$ & & $32.3(23.5-40.6)$ & \\
\hline \multicolumn{4}{|l|}{ Pathologic regional } \\
\hline LNs $(\mathrm{pN}+)$ & \multirow{4}{*}{450} & & \\
\hline No & & $97.1(49.2-142.1)$ & \multirow[t]{3}{*}{$<0.001$} \\
\hline Yes & & $32.5(27.6-44.0)$ & \\
\hline Unknown & & $20.4(15.7-26.1)$ & \\
\hline \multicolumn{4}{|l|}{ Stage } \\
\hline 1 & \multirow[t]{4}{*}{461} & $142.1(77.4-142.1)$ & \multirow[t]{4}{*}{$<0.001$} \\
\hline 2 & & $87.2(38.9-\mathrm{NR})$ & \\
\hline 3 & & $32.3(20.6-40.9)$ & \\
\hline 4 & & $14.1(10.5-20.1)$ & \\
\hline \multicolumn{4}{|l|}{ Grade } \\
\hline Well-differentiated & \multirow[t]{5}{*}{461} & $54.6(33.5-\mathrm{NR})$ & $<0.001$ \\
\hline Moderately differentiated & & $63.3(39.9-78.5)$ & \\
\hline Poorly differentiated & & $14.1(8.3-40.9)$ & \\
\hline Undifferentiated & & $4.7(2.7-75.1)$ & \\
\hline Unknown & & $23.4(18.6-29.8)$ & \\
\hline AFP & & & \\
\hline Negative & 319 & $42.9(33.5-64.6)$ & $<0.001$ \\
\hline Positive & & $18.3(11.6-23.1)$ & \\
\hline Hepatic resection & & & \\
\hline No & 433 & $10.3(7.7-13.4)$ & $<0.001$ \\
\hline Yes & & $68.5(49.2-81.8)$ & \\
\hline Chemotherapy & & & \\
\hline No & 447 & $42.8(33.7-77.4)$ & $<0.001$ \\
\hline Yes & & $22.0(18.2-28.3)$ & \\
\hline Radiation therapy & & & \\
\hline No & 457 & $34.1(28.3-41.2)$ & 0.130 \\
\hline Yes & & $22.9(13.4-26.3)$ & \\
\hline
\end{tabular}

LN: Lymph node; NR: not reached; AFP: alpha-fetoprotein, CI: confidence interval.

was not performed. Radiation therapy was not associated with outcome on a univariate basis, and therefore was excluded from the multivariable Cox proportional hazards 


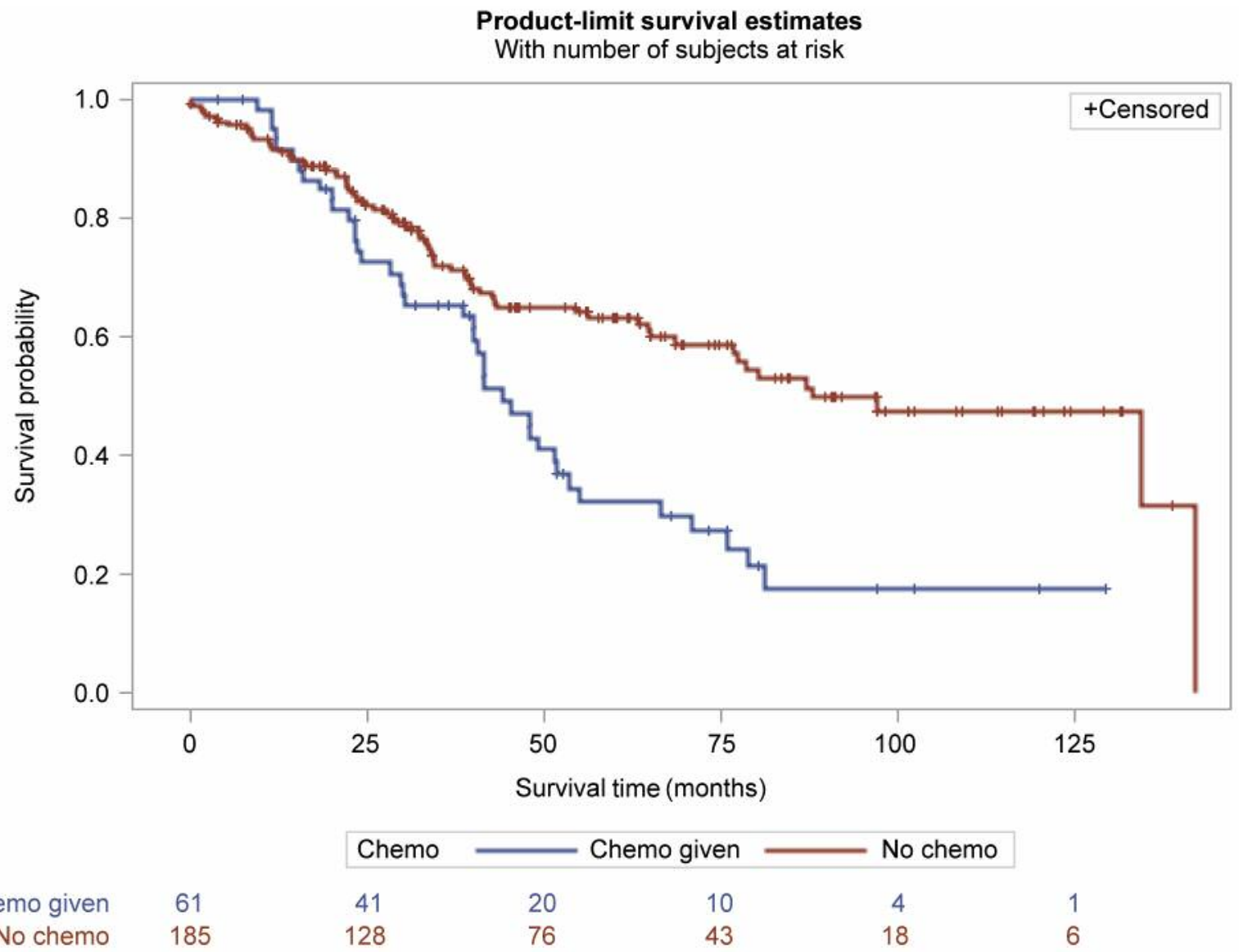

Figure 1. Kaplan-Meier curves for overall survival stratified by chemotherapy in FLC patients who received local therapy ( $n=246)$.

model analysis. Among patients with stage IV disease, there was no significant difference in median OS between those who underwent metastatectomy and those who did not $[23.4$ $(95 \% \mathrm{CI}=16.0-38.5)$ vs. $10.5 \quad(95 \% \mathrm{CI}=6.6-14.1)$ months, respectively; $p=0.163$ ] (Figure 2 ).

Multivariable analysis of outcome. We carried out a multivariable Cox Proportional Hazards analysis to control for competing clinicopathological risk factors as well as treatment modalities (Table IV). Variables that remained independently associated with OS were age at diagnosis, Charlson-Deyo comorbidity score, stage and hepatic resection. Patients who underwent surgical resection had a better prognosis than patients who did not. Patients receiving surgery had a $68 \%$ reduction in the risk of death relative to those who didn't $(p=0.001)$. Poorly differentiated FLC was associated with an increased risk of death compared to well-differentiated tumors $(\mathrm{HR}=2.35,95 \% \mathrm{CI}=1.13-4.87 ; p=0.022)$. However, there was no difference in OS when moderately differentiated $(p=0.111)$ and undifferentiated $(p=0.527)$ tumors were respectively compared to well-differentiated tumors. Gender, race, tumor size, $\mathrm{pN}+$ status, AFP level and chemotherapy were not independently associated with OS.

\section{Discussion}

To our knowledge, this retrospective analysis is the largest cancer registry-based study on fibrolamellar carcinoma. Our findings are consistent with and support previously published data on the demographic distribution and clinicopathological characteristics of FLC. In our study, $60.7 \%$ of FLC patients were diagnosed before the age of 40 , in concordance with the reported proportion of $63.2 \%$ from SEER data (26). This is in contrast to conventional HCC, where only $2-4 \%$ of cases occurred in this age group $(3,26)$. Furthermore, $69.7 \%$ of patients were Caucasian, which is slightly lower than the 83$86 \%$ range reported in other studies $(8,17)$. Data on liver cirrhosis were not available; however, $77.2 \%$ of patients had a Charlson-Deyo comorbidity score of 0 (i.e. no liver disease), supporting the notion that FLC usually occurs in healthy livers 


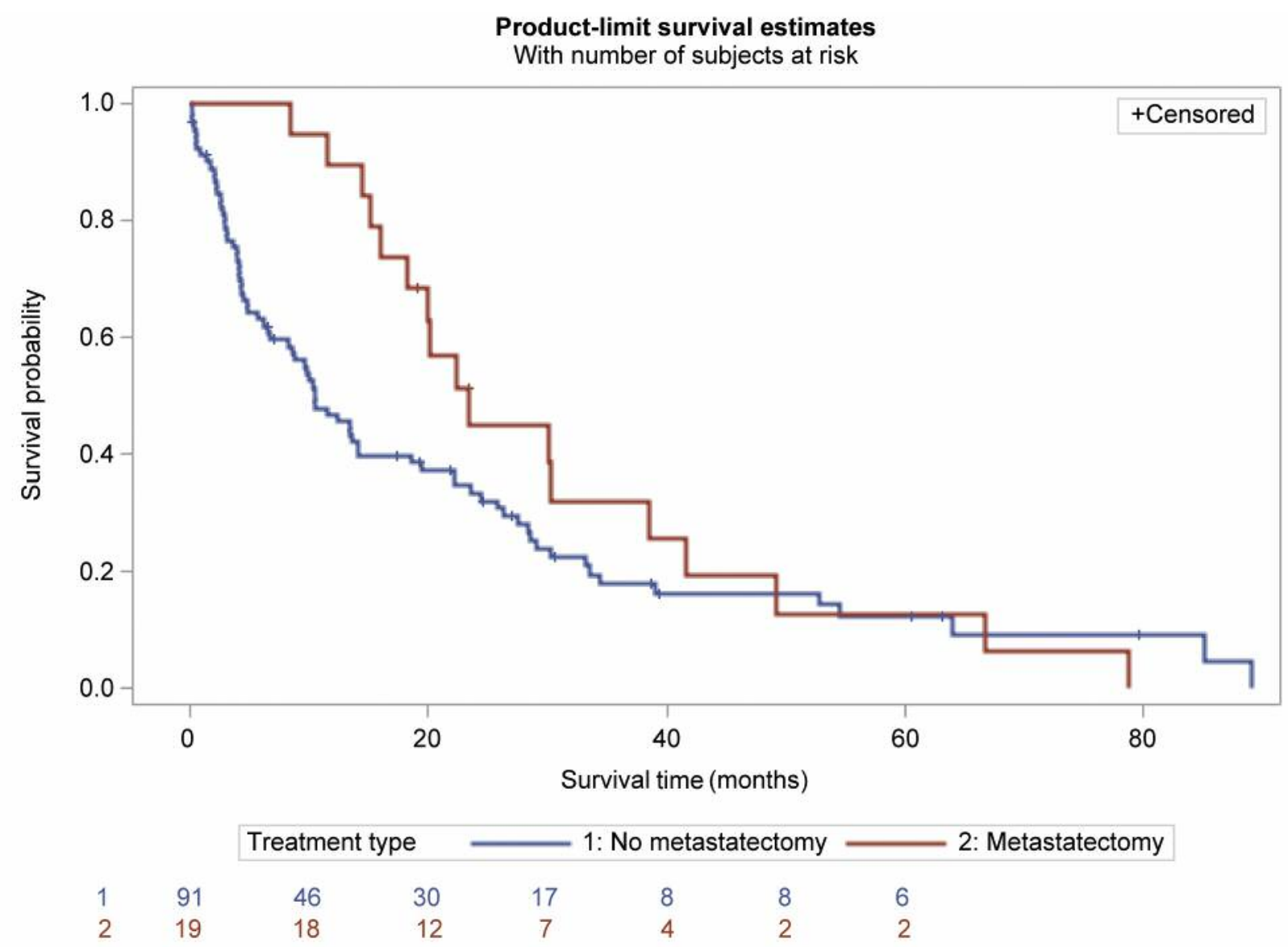

Figure 2. Kaplan-Meier curves for overall survival stratified by metastatectomy status in stage IV FLC patients $(n=110)$.

$(5,26,27)$. Concerning tumor characteristics, our results were similar to published data, with a median tumor size ranging from $9-13 \mathrm{~cm}$ and $\mathrm{pN}+$ rate of $43-46 \%(8,28,29)$. On the other hand, conventional HCC patients have a median tumor size of $6.6 \mathrm{~cm}$ and $\mathrm{pN}+$ rate of $22.1 \%(8,17)$. Proposed hypotheses for the lower rate of lymph node metastasis in conventional HCC include smaller tumor size and possible inhibition of lymphatic outflow in cirrhotic livers compared to healthy liver in FLC (30). The AFP positivity in our study was higher than previously reported values in other studies $(29.4 \% v s .7-10 \%$, respectively) $(30,31)$. This is likely due to the use of different cutoffs, as many studies use $200-400 \mathrm{ng} / \mathrm{ml}$ to represent elevation in AFP levels $(32,33)$. This could also be partially due to conventional HCC cases being misdiagnosed or miscoded as FLC.

As far as treatment is concerned, surgical resection is the treatment of choice for FLC patients $(6,18)$. The rate of LDT and liver transplantation are much lower in FLC compared to conventional HCC from the SEER database (2.6\% vs. $27.4 \%$ and $3.0 \%$ vs. $31.2 \%$, respectively) (17). FLC is not typically responsive to chemotherapy, and there are no established regimens that have shown survival benefits (5). In the metastatic setting, sorafenib, although approved for first-line treatment in conventional $\mathrm{HCC}$, has shown conflicting results in FLC patients $(34,35)$. A recent retrospective study by Chakrabarti et al., which included 42 FLC patients, showed stable disease in 4 out of 9 unresectable FLC patients who received sorafenib (35). Other regimens used in this study include gemcitabine, doxorubicin, cisplatin-based doublet, and 5-FU/folinic acid/oxaliplatin, although meaningful conclusions on their respective benefit cannot be drawn due to the very small sample sizes (35). In the peri-operative setting, chemotherapy was used in an attempt to downstage FLC in one case report, which eventually lead to curative resection (21). However, other studies did not reflect this benefit (8, $35)$. As for the role of radiation therapy, it remains poorly defined in FLC (5). In a retrospective study of 10 unresectable metastatic FLC patients treated with external beam radiotherapy in addition to chemotherapy, objective partial response and tumor stabilization were achieved in 
Table IV. Cox proportional hazards model-multivariable analysis.

\begin{tabular}{|c|c|c|c|}
\hline Characteristic & Hazard ratio & $95 \% \mathrm{CI}$ & $p$-Value \\
\hline \multicolumn{4}{|l|}{ Age (years) } \\
\hline$<40$ & Ref & Ref & \\
\hline$\geq 40$ & 1.56 & $1.08-2.25$ & 0.019 \\
\hline \multicolumn{4}{|l|}{ Gender } \\
\hline Male & Ref & Ref & \\
\hline Female & 0.92 & $0.70-1.21$ & 0.542 \\
\hline \multicolumn{4}{|l|}{ Race } \\
\hline White & Ref & Ref & \\
\hline Black & 1.40 & $0.96-2.05$ & 0.081 \\
\hline Hispanic & 1.45 & $1.00-2.11$ & 0.051 \\
\hline Other & 1.30 & $0.82-2.06$ & 0.268 \\
\hline \multicolumn{4}{|l|}{ Charlson-Deyo score } \\
\hline 0 & Ref & Ref & \\
\hline 1 & 1.25 & $0.83-1.90$ & 0.289 \\
\hline 2 & 2.39 & $1.22-4.67$ & 0.011 \\
\hline 3 & 6.66 & $3.91-11.4$ & $<0.001$ \\
\hline \multicolumn{4}{|l|}{ Tumor size } \\
\hline$<10 \mathrm{~cm}$ & Ref & Ref & \\
\hline$\geq 10 \mathrm{~cm}$ & 1.16 & $0.87-1.54$ & 0.318 \\
\hline \multicolumn{4}{|l|}{ Pathologic regional LNs $(\mathrm{pN}+)$} \\
\hline No & Ref & Ref & \\
\hline Yes & 1.25 & $0.72-2.17$ & 0.423 \\
\hline Unknown & 0.76 & $0.45-1.28$ & 0.304 \\
\hline \multicolumn{4}{|l|}{ Stage } \\
\hline 1 & Ref & Ref & \\
\hline 2 & 1.26 & $0.69-2.30$ & 0.447 \\
\hline 3 & 2.69 & $1.70-4.27$ & $<0.001$ \\
\hline 4 & 4.56 & $2.74-7.59$ & $<0.001$ \\
\hline \multicolumn{4}{|l|}{ Grade } \\
\hline Well-differentiated & Ref & Ref & \\
\hline Moderately differentiated & 1.62 & $0.90-2.92$ & 0.111 \\
\hline Poorly differentiated & 2.35 & $1.13-4.87$ & 0.022 \\
\hline Undifferentiated & 1.53 & $0.41-5.71$ & 0.527 \\
\hline Unknown & 1.81 & $1.05-3.11$ & 0.032 \\
\hline \multicolumn{4}{|l|}{ AFP } \\
\hline Negative & Ref & Ref & \\
\hline Positive & 0.96 & $0.65-1.40$ & 0.820 \\
\hline \multicolumn{4}{|l|}{ Hepatic resection } \\
\hline No & Ref & & \\
\hline Yes & 0.32 & $0.21-0.50$ & $<0.001$ \\
\hline \multicolumn{4}{|l|}{ Chemotherapy } \\
\hline No & Ref & & \\
\hline Yes & 1.04 & $0.76-1.43$ & 0.821 \\
\hline
\end{tabular}

CI: Confidence interval; Ref: reference; AFP: alpha-fetoprotein.

$30 \%$ and $60 \%$, respectively (36). In our study, however, radiation therapy was not associated with improved OS.

We reported univariate analyses of OS using demographic, clinicopathological and treatment variables. As per previous studies, the median OS varied significantly based on disease stage, ranging from 14.1 to 142.1 months. A systematic review by Mavros et al. showed a similar median OS range of 14 to 112 months. Compared to FLC, conventional HCC appears to have worse outcome, with median OS range from 8 to 39 months at best in patients with non-cirrhotic livers $(18,30,37)$. Whether the superior survival outcomes of FLC is due to the differential tumor biology compared to conventional HCC is a matter of debate (38). A meta-analysis of 11 studies by Njei et al. showed that the survival advantage is no longer present when a subset analysis of non-cirrhotic HCC patients was compared to FLC patients $(\mathrm{HR}=1.69 ; 95 \% \mathrm{CI}=0.69-4.17$; $p=0.25$ ) (18). On the other hand, Eggert et al. found that FLC patients less than 40 years of age are more likely to receive curative treatments than conventional HCC $(59 \%$ vs. $32 \%, p=0.001$ ), which may be partly due to limitation of therapeutic options in HCC due to underlying liver disease (3). Therefore, among patients who received curative treatments, there was no difference in the 5-year relative survival between FLC and conventional HCC (56.8\% vs. $51.1 \%$ ) (3). Looking at the addition of chemotherapy to local therapy, our study showed that peri-operative chemotherapy was associated with worse OS (Figure 1). Pinna et al. also found that adjuvant chemotherapy decreased tumor-free survival (39). This may in part reflect the selection to give chemotherapy in higher risk patients. Indeed, chemotherapy lost its prognostic significance when multivariable analysis was performed. Metastatectomy was evaluated in one study where 18 patients undergoing the procedure had superior OS compared to their non-resected metastatic counterparts (40). We were not able to replicate this finding in our study.

Elucidating prognostic clinicopathological factors in FLC is of paramount importance to allow clinicians to gain insight into the natural history of the disease. Moreover, they can serve to better inform patients and their families about the risk of death from this rare entity. Since the rarity of FLC precludes from performing prospective or single-center studies, retrospective analysis is necessary in delineating the clinical behavior of FLC. Yamashita et al. reported vascular invasion and number of tumors as prognostic factors, and Darcy et al. proposed disease stage and $\mathrm{pN}+$ status; however, both these studies were performed on a univariate analysis basis $(8,41)$. Only 1 out of 8 studies reported in the systematic review by Mavros et al. assessed prognostic factors using multivariable analysis, which suggested age and resectability as independent predictors of survival $(29,42)$. Our study showed that independent predictors of OS in patients with FLC, after controlling for covariates, include age at diagnosis, Charlson-Deyo comorbidity score, stage and hepatic resection.

The current study has several limitations. Most importantly, the retrospective nature of data precludes the ability to make definite recommendations on management of FLC. Also, no direct comparison was done between FLC and conventional HCC cases from the NCDB. Moreover, the NCDB does not record data on progression-free survival and disease-specific mortality, which would have been interesting outcomes to analyze. Another limitation is the grading of tumors, which 
not only was missing in a significant proportion of patients, but also lacked centralized pathology review. That being said, the NCDB undergoes extensive data quality checks, ensuring accurate diagnosis. Moreover, treatment details such as the type of chemotherapy, the number of cycles, and radiation dose are not reported in the NCDB. Although important, these details would not have a major effect on our findings. Nevertheless, our data shed light on the general trends in management and prognosis of patients with rare tumors such as FLC. By using a national database such as the NCDB, a sufficient patient population is created to identify important associations with FLC outcomes.

In summary, this study provides new insight into overall survival in different subpopulations of FLC patients. Our data showed that peri-operative chemotherapy did not seem to improve OS in FLC patients. Furthermore, there was no associated survival benefit with metastatectomy in patients with stage IV disease. Further investigation, ideally with prospective evaluation, is warranted to validate these findings.

\section{Conflicts of Interest}

The Authors of this manuscript have no conflicts of interest to declare.

\section{Authors' Contributions}

Hussein Assi: Conceptualization, data curation, formal analysis, software, writing - original draft, and writing - review and editing. Sarbajit Mukherjee: Conceptualization, data curation, methodology, project administration, writing - original draft, and writing - review and editing. Michael Machiorlatti: Methodology, data curation, formal analysis, software, and writing - review and editing. Sara Vesely: Methodology, formal analysis, software, and writing review and editing. Vipul Pareek: Supervision, project administration, and writing - review and editing. Hassan Hatoum: Conceptualization, supervision, formal analysis, writing - original draft, and writing - review and editing.

\section{Acknowledgements}

The Authors wish to thank the American College of Surgeons and the Commission on Cancer for providing data from the National Cancer Database (NCDB). The NCDB is a joint project of the Commission on Cancer of the American College of Surgeons and the American Cancer Society. The American College of Surgeons and the Commission on Cancer have not verified and are not responsible for the analytic or statistical methodology employed, or the conclusions drawn from these data by the investigator. We would also like to thank Nancy Etzold for her help with obtaining the NCDB data.

\section{References}

1 Siegel RL, Miller KD and Jemal A: Cancer statistics, 2019. CA Cancer J Clin 69(1): 7-34, 2019. PMID: 30620402. DOI: $10.3322 /$ caac. 21551
2 Cronin KA, Lake AJ, Scott S, Sherman RL, Noone AM, Howlader N, Henley SJ, Anderson RN, Firth AU, Ma J, Kohler BA and Jemal A: Annual report to the nation on the status of cancer, part i: National cancer statistics. Cancer 124(13): 27852800, 2018. PMID: 29786848. DOI: 10.1002/cncr.31551

3 Eggert T, McGlynn KA, Duffy A, Manns MP, Greten TF and Altekruse SF: Fibrolamellar hepatocellular carcinoma in the USA, 2000-2010: A detailed report on frequency, treatment and outcome based on the surveillance, epidemiology, and end results database. United European Gastroenterol J 1(5): 351-357, 2013. PMID: 24917983. DOI: $10.1177 / 2050640613501507$

4 Graham RP: Fibrolamellar carcinoma: What is new and why it matters. Surg Pathol Clin 11(2): 377-387, 2018. PMID: 29751881. DOI: $10.1016 /$ j.path.2018.02.006

5 Lafaro KJ and Pawlik TM: Fibrolamellar hepatocellular carcinoma: Current clinical perspectives. J Hepatocell Carcinoma 2: 151-157, 2015. PMID: 27508204. DOI: 10.2147/jhc.S75153

6 Kassahun WT: Contemporary management of fibrolamellar hepatocellular carcinoma: Diagnosis, treatment, outcome, prognostic factors, and recent developments. World J Surg Oncol 14(1): 151, 2016. PMID: 27215576. DOI: 10.1186/s12957-0160903-8

7 Andersen JB: Fibrolamellar hepatocellular carcinoma: A rare but distinct type of liver cancer. Gastroenterology 148(4): 707-710, 2015. PMID: 25724459. DOI: 10.1053/j.gastro.2015.02.039

8 Yamashita S, Vauthey JN, Kaseb AO, Aloia TA, Conrad C, Hassan MM, Passot G, Raghav KP, Shama MA and Chun YS: Prognosis of fibrolamellar carcinoma compared to non-cirrhotic conventional hepatocellular carcinoma. J Gastrointest Surg 20(10): 1725-1731, 2016. PMID: 27456016. DOI: $10.1007 /$ s11605-016-3216-x

9 Honeyman JN, Simon EP, Robine N, Chiaroni-Clarke R, Darcy DG, Lim, II, Gleason CE, Murphy JM, Rosenberg BR, Teegan L, Takacs CN, Botero S, Belote R, Germer S, Emde AK, Vacic V, Bhanot U, LaQuaglia MP and Simon SM: Detection of a recurrent dnajb1-prkaca chimeric transcript in fibrolamellar hepatocellular carcinoma. Science 343(6174): 1010-1014, 2014. PMID: 24578576. DOI: 10.1126/science. 1249484

10 Edmondson HA: Differential diagnosis of tumors and tumor-like lesions of liver in infancy and childhood. AMA J Dis Child 91(2): 168-186, 1956. PMID: 13282629. DOI: 10.1001/archpedi.1956. 02060020170015

11 Lim, II, Farber BA and LaQuaglia MP: Advances in fibrolamellar hepatocellular carcinoma: A review. Eur J Pediatr Surg 24(6): 461466, 2014. PMID: 25486412. DOI: 10.1055/s-0034-1396420

12 Goumard C, Desbois-Mouthon C, Wendum D, Calmel C, Merabtene F, Scatton O and Praz F: Low levels of microsatellite instability at simple repeated sequences commonly occur in human hepatocellular carcinoma. Cancer Genomics Proteomics 14(5): 329-339, 2017. PMID: 28871000. DOI: $10.21873 / \operatorname{cgp} .20043$

13 Meerzaman DM, Yan C, Chen QR, Edmonson MN, Schaefer CF, Clifford RJ, Dunn BK, Dong L, Finney RP, Cultraro CM, Hu Y, Yang Z, Nguyen CV, Kelley JM, Cai S, Zhang H, Zhang J, Wilson R, Messmer L, Chung YH, Kim JA, Park NH, Lyu MS, Song IH, Komatsoulis G and Buetow KH: Genome-wide transcriptional sequencing identifies novel mutations in metabolic genes in human hepatocellular carcinoma. Cancer Genomics Proteomics 11(1): 1-12, 2014. PMID: 24633315.

14 Mafeld S, French J, Tiniakos D, Haugk B, Manas D and Littler P: Fibrolamellar hepatocellular carcinoma: Treatment with 
yttrium-90 and subsequent surgical resection. Cardiovasc Intervent Radiol 41(5): 816-820, 2018. PMID: 29468286. DOI: 10.1007/s00270-018-1903-6

15 Ince V, Isik B, Ozdemir F, Ozgor D, Ara C and Yilmaz S: Living-donor liver transplant for fibrolamellar hepatocellular carcinoma with hilar lymph node metastasis: A case report. Exp Clin Transplant, 2018. PMID: 29633928. DOI: 10.6002/ect.2017.0040

16 Chaudhari IA, Khobragade K, Bhandare M and Shrikhande SV: Management of fibrolamellar hepatocellular carcinoma. Chin Clin Oncol 7(5): 51, 2018. PMID: 30395718. DOI: 10.21037/cco.2018.08.08

17 Mayo SC, Mavros MN, Nathan H, Cosgrove D, Herman JM, Kamel I, Anders RA and Pawlik TM: Treatment and prognosis of patients with fibrolamellar hepatocellular carcinoma: A national perspective. J Am Coll Surg 218(2): 196-205, 2014. PMID: 24315886. DOI: 10.1016/j.jamcollsurg.2013.10.011

18 Njei B, Konjeti VR and Ditah I: Prognosis of patients with fibrolamellar hepatocellular carcinoma versus conventional hepatocellular carcinoma: A systematic review and meta-analysis. Gastrointest Cancer Res 7(2): 49-54, 2014. PMID: 24799971.

19 Cho E, Cho HA, Jun CH, Kim HJ, Cho SB and Choi SK: A review of hepatocellular carcinoma in elderly patients focused on management and outcomes. In Vivo 33(5): 1411-1420, 2019. PMID: 31471386. DOI: 10.21873/invivo.11618

20 Tanaka H, Hijioka S, Iwaya H, Mizuno N, Kuwahara T, Okuno N, Ito A, Kuraoka N, Matsumoto S, Obata M, Kurita Y, Yasuda M, Shimizu Y, Kuroda H, Sato Y, Haneda M, Sasaki E, Yatabe $\mathrm{Y}$ and Hara K: Fibrolamellar hepatocellular carcinoma with multiple lung metastases treated with multidisciplinary therapy. Intern Med 57(24): 3537-3543, 2018. PMID: 30101933. DOI: 10.2169/internalmedicine.1243-18

21 Fonseca GM, Varella AD, Coelho FF, Abe ES, Dumarco RB and Herman P: Downstaging and resection after neoadjuvant therapy for fibrolamellar hepatocellular carcinoma. World J Gastrointest Surg 6(6): 107-111, 2014. PMID: 24976904. DOI: 10.4240/wjgs. v6.i6.107

22 Maniaci V, Davidson BR, Rolles K, Dhillon AP, Hackshaw A, Begent RH and Meyer T: Fibrolamellar hepatocellular carcinoma: Prolonged survival with multimodality therapy. Eur J Surg Oncol 35(6): 617-621, 2009. PMID: 19144491. DOI: 10.1016/j.ejso.2008.12.009

23 International Classification of Diseases for Oncology: International Agency for Research on Cancer. Geneva, World Health Organization, 2013. Available at: https://appswhoint/iris/handle/ 10665/96612 (Last accessed on 16th January 2020)

24 Concept: Charlson Comorbidity Index. Winnipeg, Manitoba Centre for Health Policy, 2019. Available at: http://mchpappservcpeumanitobaca/viewConceptphp?conceptID=1098 (Last accessed on 16th January 2020)

25 Marrero JA, Kulik LM, Sirlin CB, Zhu AX, Finn RS, Abecassis MM, Roberts LR and Heimbach JK: Diagnosis, staging, and management of hepatocellular carcinoma: 2018 practice guidance by the american association for the study of liver diseases. Hepatology 68(2): 723-750, 2018. PMID: 29624699. DOI: $10.1002 /$ hep. 29913

26 El-Serag HB and Davila JA: Is fibrolamellar carcinoma different from hepatocellular carcinoma? A us population-based study. Hepatology 39(3): 798-803, 2004. PMID: 14999699. DOI: 10.1002/hep.20096
27 Engelholm LH, Riaz A, Serra D, Dagnaes-Hansen F, Johansen JV, Santoni-Rugiu E, Hansen SH, Niola F and Frodin M: Crispr/cas9 engineering of adult mouse liver demonstrates that the dnajb1-prkaca gene fusion is sufficient to induce tumors resembling fibrolamellar hepatocellular carcinoma. Gastroenterology 153(6): 1662-1673.e1610, 2017. PMID: 28923495. DOI: 10.1053/j.gastro.2017.09.008

28 Chagas AL, Kikuchi L, Herman P, Alencar RS, Tani CM, Diniz MA, Pugliese V, Rocha Mde S, D’Albuquerque LA, Carrilho FJ and Alves VA: Clinical and pathological evaluation of fibrolamellar hepatocellular carcinoma: A single center study of 21 cases. Clinics (Sao Paulo) 70(3): 207-213, 2015. PMID: 26017653. DOI: $10.6061 /$ clinics/2015(03)10

29 Mavros MN, Mayo SC, Hyder O and Pawlik TM: A systematic review: Treatment and prognosis of patients with fibrolamellar hepatocellular carcinoma. J Am Coll Surg 215(6): 820-830, 2012. PMID: 22981432. DOI: 10.1016/j.jamcollsurg.2012.08.001

30 Stipa F, Yoon SS, Liau KH, Fong Y, Jarnagin WR, D’Angelica M, Abou-Alfa G, Blumgart LH and DeMatteo RP: Outcome of patients with fibrolamellar hepatocellular carcinoma. Cancer 106(6): 13311338, 2006. PMID: 16475212. DOI: 10.1002/cncr.21703

31 Wahab MA, El Hanafy E, El Nakeeb A and Ali MA: Clinicopathological features and surgical outcome of patients with fibrolamellar hepatocellular carcinoma (experience with 22 patients over a 15-year period). World J Gastrointest Surg 9(2): 61-67, 2017. PMID: 28289511. DOI: 10.4240/wjgs.v9.i2.61

32 Arrieta O, Cacho B, Morales-Espinosa D, Ruelas-Villavicencio A, Flores-Estrada D and Hernandez-Pedro N: The progressive elevation of alpha fetoprotein for the diagnosis of hepatocellular carcinoma in patients with liver cirrhosis. BMC Cancer 7: 28, 2007. PMID: 17288606. DOI: 10.1186/14712407-7-28

33 Talwalkar JA and Gores GJ: Diagnosis and staging of hepatocellular carcinoma. Gastroenterology 127(5 Suppl 1): S126-132, 2004. PMID: 15508076. DOI: 10.1053/j.gastro. 2004.09.026

34 Ang CS, Kelley RK, Choti MA, Cosgrove DP, Chou JF, Klimstra D, Torbenson MS, Ferrell L, Pawlik TM, Fong Y, O'Reilly EM, Ma J, McGuire J, Vallarapu GP, Griffin A, Stipa F, Capanu M, Dematteo RP, Venook AP and Abou-Alfa GK: Clinicopathologic characteristics and survival outcomes of patients with fibrolamellar carcinoma: Data from the fibrolamellar carcinoma consortium. Gastrointest Cancer Res 6(1): 3-9, 2013. PMID: 23505572.

35 Chakrabarti S, Tella SH, Kommalapati A, Huffman BM, Yadav S, Riaz IB, Goyal G, Mody K, Borad M, Cleary S, Smoot RL and Mahipal A: Clinicopathological features and outcomes of fibrolamellar hepatocellular carcinoma. J Gastrointest Oncol 10(3): 554-561, 2019. PMID: 31183207. DOI: 10.21037/jgo.2019.01.35

36 Epstein BE, Pajak TF, Haulk TL, Herpst JM, Order SE and Abrams RA: Metastatic nonresectable fibrolamellar hepatoma: Prognostic features and natural history. Am J Clin Oncol 22(1): 22-28, 1999. PMID: 10025374. DOI: 10.1097/00000421199902000-00006

37 Bhaijee F, Krige JE, Locketz ML and Kew MC: Liver resection for non-cirrhotic hepatocellular carcinoma in south african patients. S Afr J Surg 49(2): 68-74, 2011. PMID: 21614976.

38 Eggert T, McGlynn K, Greten TF and Altekruse S: Response to fibrolamellar hepatocellular carcinoma versus conventional 
hepatocellular carcinoma: Better 5-year survival or artefactual result of research methodology? Gut 63(9): 1524, 2014. PMID: 24287277. DOI: 10.1136/gutjnl-2013-306407

39 Pinna AD, Iwatsuki S, Lee RG, Todo S, Madariaga JR, Marsh JW, Casavilla A, Dvorchik I, Fung JJ and Starzl TE: Treatment of fibrolamellar hepatoma with subtotal hepatectomy or transplantation. Hepatology 26(4): 877-883, 1997. PMID: 9328308. DOI: 10.1002/hep.510260412

40 Kaseb AO, Shama M, Sahin IH, Nooka A, Hassabo HM, Vauthey JN, Aloia T, Abbruzzese JL, Subbiah IM, Janku F, Curley S and Hassan MM: Prognostic indicators and treatment outcome in 94 cases of fibrolamellar hepatocellular carcinoma. Oncology 85(4): 197-203, 2013. PMID: 24051705. DOI: $10.1159 / 000354698$
41 Darcy DG, Malek MM, Kobos R, Klimstra DS, DeMatteo R and La Quaglia MP: Prognostic factors in fibrolamellar hepatocellular carcinoma in young people. J Pediatr Surg 50(1): 153-156, 2015. PMID: 25598114. DOI: 10.1016/j.jpedsurg.2014.10.039

42 Moreno-Luna LE, Arrieta O, Garcia-Leiva J, Martinez B, Torre A, Uribe $M$ and Leon-Rodriguez E: Clinical and pathologic factors associated with survival in young adult patients with fibrolamellar hepatocarcinoma. BMC Cancer 5: 142, 2005. PMID: 16259635. DOI: 10.1186/1471-2407-5-142

Received January 7, 2020

Revised January 17, 2020

Accepted January 20, 2020 